\title{
Synthesis of Novel Polydiazocine for Electroactive Materials Based on Diazocine
}

\author{
Jianzhong Li, ${ }^{1}$ Xiaobo Wan ${ }^{2}$ \\ ${ }^{1}$ College of Chemistry and Pharmaceutical Sciences, Qingdao Agricultural University, Qingdao 266109, \\ People's Republic of China \\ ${ }^{2}$ Qingdao Institute of Bioprocess Technology, Chinese Academy of Sciences, Qingdao 266101, \\ People's Republic of China \\ Correspondence to: Jianzhong Li (E-mail: jianzhongli@aliyun.com)
}

Received 10 April 2013; accepted 1 August 2013; published online 20 August 2013

DOI: 10.1002/pola.26891

ABSTRACT: In this study, we successfully designed and synthesized a novel class of ladder-type polymer polydibenzoyl[b,f][1,5]diazocine (PBDA-a) and polydimethoxybenzoyl $[b, f][1,5]$ diazocines (PBDA-b) for novel electrochemical actuators via one-pot polymerization. The structure of polymers was characterized using ${ }^{13} \mathrm{C}$ NMR, FTIR and MALDI-TOF. Both of the polydiazocines exhibited high thermal stability and excellent solubility in common solvent. Molecular conformation studies using the density functional theory method revealed that the conformational structure of PBDA-a preferred to dis- play zigzag conformation while PBDA-b display helix conformation. The mechanism of the polydiazocine synthesis is assumed to condensation polymerization proceeding by an unprecedented cyclization of the isocyanate with the neighboring acyl group, followed by the dimerization to form diazocine ring. (c) 2013 Wiley Periodicals, Inc. J. Polym. Sci., Part A: Polym. Chem. 2013, 51, 4694-4701

KEYWORDS: heteroatom-containing polymers; nonlinear polymers; oligomers; polycondensation; synthesis
INTRODUCTION Electrochemical actuators are materials respond to an electrochemical signal, by a structural distortion that can be transduced into mechanical work. ${ }^{1}$ Efforts have been paid to develop efficient organic mechanical actuators in recent years, since these materials could provide the basis for the assembly of artificial muscles, molecular switches and motors, and other related nanodevices. ${ }^{2-5}$ Conducting polymers, such as polypyrrole and polythio-phene, are among the most successful materials to be used in the synthesis of electrochemical actuators. ${ }^{6-8}$ The electrochemical actuation of these materials is based on volume changes that result from the uptake or expulsion of counterions of the polymer during a redox cycle. ${ }^{9}$ It is a bulk property of redox-active polymers, which is not necessarily an intrinsic property of individual polymer chains. Such bulk mechanism, though, carries a number of limitations: the small linear strain that can be achieved, the low actuation frequency (limited by the diffusion of ions), and the complex nature of the actuation. All of these drawbacks compromise at some point the applicability of these systems in nanomechanical devices. ${ }^{10}$

Recent efforts have been directed towards the design of a new conceptionally different class of actuators, the actuation mechanism of which is based on the reversible conforma- tional changes at the single molecular level, not on mass transport and induced swelling. Many syntheses of these actuator materials such as cyclooctatetrathiophene, ${ }^{11,12}$ thiepin, ${ }^{13}$ and azepine ${ }^{14}$ and their applications in electrochemical active polymeric materials, have been reported in the past decade. Such molecules and their heteroderivatives, focusing on $4 n \pi$ type rigid anti-aromatic annulenes, theoretically can undergo reversible conformational changes upon reduction or oxidation to $(4 n \pm 2) \pi$ aromatic states, and could act as the hinge segment in conjugated polymers. Therefore, they might be used as a hinge in new electroactive materials for actuation. ${ }^{10}$ Some major advantages that molecular actuators could offer over bulk actuators include shorter reaction times, increased linear strain, ease of addressability, anisotropy, and potential for implementation at the single-molecule level.

Hetero[8]annulene, diazocine, also falls into such a compound category since it has $8 \pi$ electrons in its macrocyle and could be reduced to $10 \pi$ electrons anion. ${ }^{15}$ [1,5]Diazocine (Scheme 1), which provides dynamic segmental motion resulting from its bulky nature and unique conformational characteristics, are expected to exhibit the boat-(neutral state) to planar-(dianion) conformational change via a two electron transfer process. ${ }^{16-18}$ This dynamic conformational 


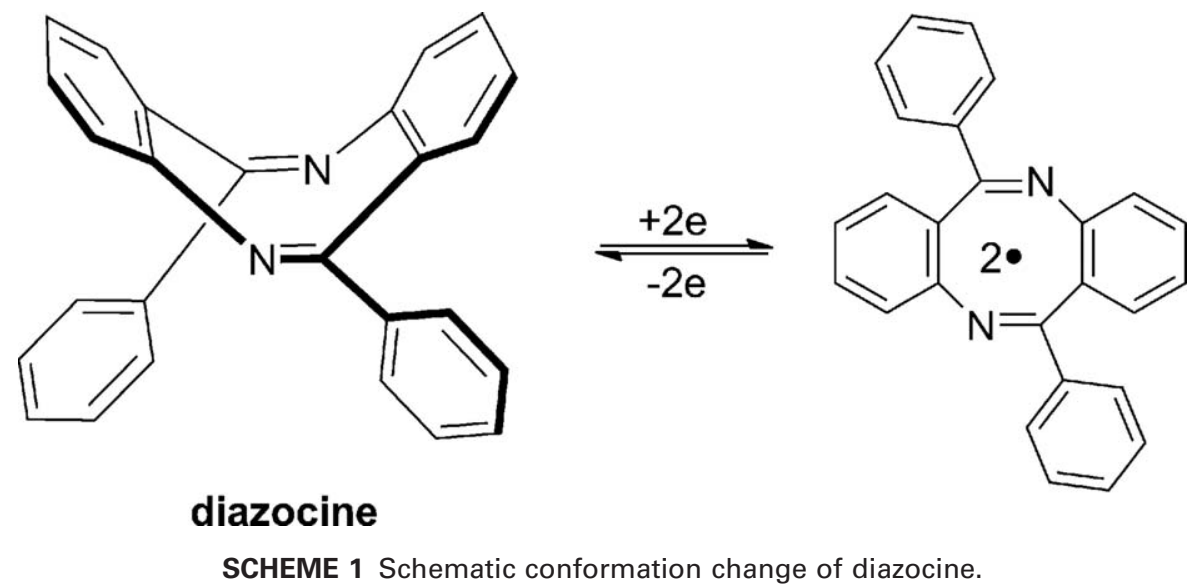

change at the molecular level has also attracted significant interest as a basis for molecular machines. Indeed, dibenzo $[b, f][1,5]$ diazocine has found its unique electrochemical property in polysulfones as a co-monomer with excellent thermal stability and mechanical properties. ${ }^{19,20}$

Recently, oligo-Tröger's base, another kind of diazocine has been reported via one-pot reaction. Especially, the one-pot reaction method encourages us designing and studying of novel pentacyclic heterocycle. However, the synthetic process only allowed access to oligo-Tröger's base such as trimeric $(n=2)$. The formation of tetra-TB $(n=3)$ and penta-TB $(n$ $=4$ ) only can be shown as trace products by the MS analysis. $^{21}$ Recently, we developed a new and efficient one-pot reaction for the synthesis of dibenzoen[b,f][1,5] diazocine. ${ }^{22}$ The mechanism of the diazocine synthesis is assumed to proceed by an unprecedented cyclization of the isocyanate with the neighboring acyl group, followed by an unprecedented dimerization, which has been strongly supported by experimental evidences in our previous work. ${ }^{23}$ Here, we focus on the further applications of this reaction to prepare novel ladder-like heterocycles polymers, polydiazocines (Fig. 1).

The novel polydiazocines are very different from conventional polymers. They are comprised of several diazocine units and phenyl rings, which are interconnected together using mutual carbon atoms affording a ladder-like structure. The new polymer material may exhibit dynamic conformational change during a redox cycle, which may be used in electrochemical actuator field. The new polydibenzo[1,5]diazocines also have attractive properties, such as high $T_{\mathrm{g}}\left(>280{ }^{\circ} \mathrm{C}\right)$ and excellent solubility in common organic solvents, that make them potentially suitable for electronics and other applications.

\section{EXPERIMENTAL}

\section{General}

All glass wares were thoroughly oven-dried. Chemicals and solvents were either purchased from commercial suppliers or purified by standards techniques. Flash chromatography was carried out utilizing silica gel 100 to 200 mesh. ${ }^{1} \mathrm{H}$ and ${ }^{13} \mathrm{C}$ NMR spectra were recorded on a Bruker Avance $600 \mathrm{MHz}$ spectrometer using tetramethylsilane (TMS) $(\delta=0.00 \mathrm{ppm})$ as an internal chemical shift standard and $\mathrm{CDCl}_{3}$ as the internal standard $(\delta=77.00 \mathrm{ppm})$ for ${ }^{13} \mathrm{C}$ NMR. Chemical shifts are given in $\delta$ relative to tetramethylsilane (TMS), the coupling constants $J$ are given in Hz. FT-IR measurements were carried out on a Nicolet iN10 FTIR spectrometer. UV-Vis absorption spectra were performed on a PerkinElmer Lambda 35 spectrometer. Gel permeation chromatography (GPC) analysis of the molecular weight and polydispersity (PDI) were measured on a Waters Breeze instrument using standard polystyrene as the reference and THF as the eluent. Thermal gravity analyses (TGA) were carried out on a TA Instrument Q600 analyzer with a heating rate of $10{ }^{\circ} \mathrm{C} / \mathrm{min}$ under an inert atmosphere. Differential scanning calorimetry analyses (DSC) were recorded on a METTLER TOLEDO Instrument DSC822 calorimeter with a heating/ cooling rate of $10{ }^{\circ} \mathrm{C} / \mathrm{min}$ under an inert atmosphere. Cyclic voltammetry was performed using a normal potentiostat system (CH Instruments, Inc., CHI620B) with a conventional three-electrode cell under a dry nitrogen atmosphere. A glassy carbon, platinum wire, and $\mathrm{Ag} / \mathrm{Ag}+$ were used as the working, auxiliary and reference electrode, respectively.

\section{2,5-Dibenzoylterephthalic acid (1a)}

In a $500 \mathrm{~mL}$ three-neck, round-bottom flask equipped with a mechanical stirrer and a water-cooled condenser were added pyromellitic dianhydride (13 g, $0.01 \mathrm{~mol}$ ), anhydrous aluminum chloride (32.0 g, $0.04 \mathrm{~mol}), 150 \mathrm{~mL}$ of benzene. The reaction mixture was heated to reflux and stirred for $24 \mathrm{~h}$. The hot reaction mixture was cooled to room temperature, poured onto $300 \mathrm{~g}$ of crushed ice containing $90 \mathrm{~mL}$ of concentrated hydrochloric acid and stirred for $2 \mathrm{~h}$. The precipitated compound was filtered, washed with water, and dried under vacuum. The obtained two isomers were separated by fractional recrystallization from ice acetic acid.

Yield: 34\%. ${ }^{1} \mathrm{H}$ NMR (600 MHz, acetone- $d 6, \delta$ ), 12.04(s, 2H), $8.10(\mathrm{~s}, 2 \mathrm{H}), 7.84-7.86(\mathrm{~d}, J=7.51 \mathrm{~Hz}, 4 \mathrm{H}), 7.65-7.68(\mathrm{t}$, $4 \mathrm{H})$, 7.53-7.56 $(\mathrm{t}, 4 \mathrm{H})$. Anal. CalcD for $\mathrm{C}_{22} \mathrm{H}_{14} \mathrm{O}_{6}$ : $\mathrm{C} 70.59, \mathrm{H}$ 3.77; found: C 70.72, H 3.82.

\section{2,5-Bis(4-methoxybenzoyl)terephthalic acid (1b)}

Compound $1 \mathrm{~b}$ was synthesized by a similar method as that of compound 1a. The obtained two isomers were separated by fractional recrystallization from ice acetic acid. 


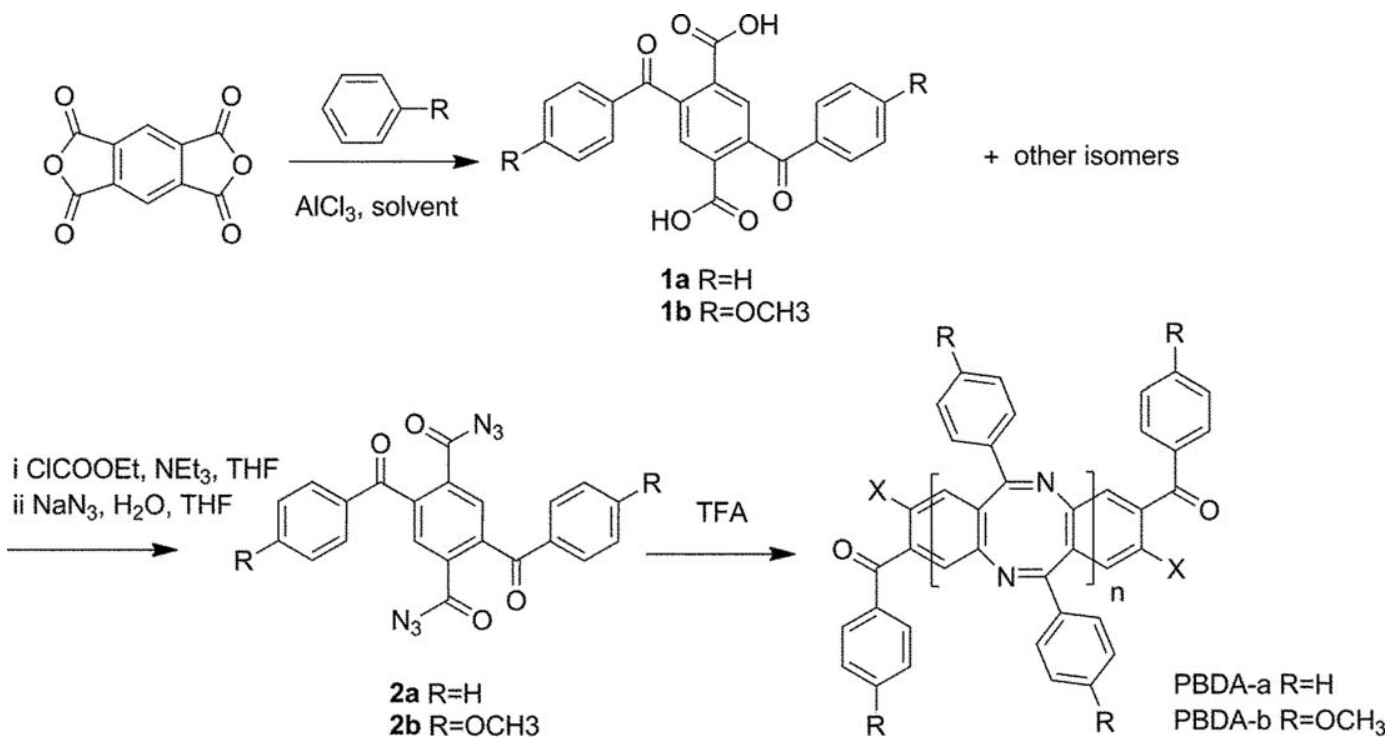

SCHEME 2 Synthetic routes to polydiazocines.

Yield: 32\%. ${ }^{1} \mathrm{H}$ NMR (600 MHz, DMSO-d6, $\delta$ ), 13.66 (s, 2H), $7.81(\mathrm{~s}, 2 \mathrm{H}), 7.72-7.74(\mathrm{~d}, J=8.8 \mathrm{~Hz}, 4 \mathrm{H}), 7.07-7.08(\mathrm{~d}, J=$ $8.9 \mathrm{~Hz}, 4 \mathrm{H}), 3.86(\mathrm{~s}, 6 \mathrm{H})$. Anal. CAlCD for $\mathrm{C}_{24} \mathrm{H}_{18} \mathrm{O}_{8}$ : C 66.36, H 4.18; found: C 66.54, H 4.24 .

\section{2,5-Dibenzoylterephthalic azide (2a)}

To a solution of compound $1 \mathrm{a}(1.20 \mathrm{~g}, 3.2 \mathrm{mmol})$ in anhydrous THF (40mL) was added $\mathrm{Et}_{3} \mathrm{~N}(1.78 \mathrm{~mL}, 12.8 \mathrm{mmol})$ and ethyl chloroformate (1.22 $\mathrm{g}, 12.8 \mathrm{mmol})$ in an ice bath. The mixture was stirred for $4 \mathrm{~h}$, and then was added sodium azide $(0.81 \mathrm{~g}, 12.8 \mathrm{mmol})$ in water $(1 \mathrm{~mL})$. The reaction mixture was stirred for $12 \mathrm{~h}$ in an ice bath and concentrated. The residue was dissolved in dichloromethane $(50 \mathrm{~mL})$ and the solution was washed with water twice, separated, dried $\left(\mathrm{MgSO}_{4}\right)$, and concentrated. Further purification was carried out using recrystallization from dichloromethane.

Yield: $69.0 \%$. IR (KBr) $\mathrm{cm}^{-1}: \quad 1673\left(\mathrm{w}, v_{\mathrm{C}=\mathrm{ON} 3}\right), 1574$ $\left(v_{\mathrm{C}=\mathrm{C}, \mathrm{Ar}}\right) .{ }^{1} \mathrm{H}$ NMR $\left(600 \mathrm{MHz}, \mathrm{CDCl}_{3}, \delta\right), 8.05(\mathrm{~s}, 2 \mathrm{H}), 7.79-$ $7.81(\mathrm{~d}, J=8.8 \mathrm{~Hz}, 4 \mathrm{H}), 7.65-7.67(\mathrm{~m}, 2 \mathrm{H}), 7.51-7.54$ (m, 4H); ${ }^{13} \mathrm{C}$ NMR (600 MHz, $\left.\mathrm{CDCl}_{3}, \delta\right) 194.78\left(\mathrm{C}=\mathrm{ON}_{3}\right)$, $170.55,143.21,135.98,134.12,133.46,129.61,129.59$, 128.95; Anal. CALCD for $\mathrm{C}_{22} \mathrm{H}_{12} \mathrm{~N}_{6} \mathrm{O}_{4}$ : C 62.27, $\mathrm{H} 2.85, \mathrm{~N}$ 19.80; found: C 62.42, H 2.82, N 19.95.

\section{2,5-Bis(4-(methoxy)benzoyl)terephthalic azide (2b)}

Compound $2 \mathrm{~b}$ was synthesized by a similar method as that of compound 2a. Purification was carried out using column chromatography $\left(\mathrm{CH}_{2} \mathrm{Cl}_{2}\right.$ /petroleum ether $\left.=2: 3\right)$.

Yield: 78\%. IR (KBr) cm ${ }^{-1}$ : $1673\left(\mathrm{w}, v_{\mathrm{C}=\mathrm{ON} 3}\right), 1574\left(v_{\mathrm{C}=\mathrm{C}, \mathrm{Ar}}\right)$; ${ }^{1} \mathrm{H}$ NMR $\left(600 \mathrm{MHz}, \mathrm{CDCl}_{3}, \delta\right), 8.02(\mathrm{~s}, 2 \mathrm{H}), 7.76-7.77(\mathrm{~d}, \mathrm{~d}$, $J=8.8 \mathrm{~Hz}, 4 \mathrm{H}), 6.97-6.99(\mathrm{~d}, \mathrm{~d}, J=8.9 \mathrm{~Hz}, 4 \mathrm{H}), 3.81(\mathrm{~s}$, $6 \mathrm{H}) ;{ }^{13} \mathrm{C}$ NMR (600 MHz, $\left.\mathrm{CDCl}_{3}, \delta\right) 193.44\left(\mathrm{C}=\mathrm{ON}_{3}\right), 170.65$, $164.33,143.29,133.25,132.05,129.64,129.09,114.22$, 55.67; Anal. CalCD for $\mathrm{C}_{24} \mathrm{H}_{16} \mathrm{~N}_{6} \mathrm{O}_{6}$ : C59.51, H 3.33, N 17.35; found: C 59.72, H 3.35, N 17.52 .

\section{Polydibenzoyl[1,5]-diazocine (PBDA-a)}

Compound 2a (0.32 g, $0.75 \mathrm{mmol})$ was added to trifluoroacetic acid (TFA) (5 mL), and the mixture was heated up to 80 ${ }^{\circ} \mathrm{C}$ and stirred for $12 \mathrm{~h}$. The reaction mixture was then cooled down to room temperature, neutralized with saturated $\mathrm{Na}_{2} \mathrm{CO}_{3}$ solution, and extracted with dichloromethane $(3 \times 20 \mathrm{~mL})$. The combined organic layer was washed with brine and dried over anhydrous $\mathrm{MgSO}_{4}$. The solvent was evaporated and yellow powder the residue was purified using column chromatography to afford the corresponding products as yellow powder. $\left(\mathrm{CH}_{2} \mathrm{Cl}_{2} /\right.$ petroleum ether $=2: 3$; $\mathrm{CH}_{2} \mathrm{Cl}_{2}$ /ethyl acetate $=20: 1$ ). Yield: $78 \%$.

\section{Polydimethoxybenzoyl[1,5]diazocines (PBDA-b)}

This was synthesized in a similar method as that of PBDA-a. The product was purified using column chromatography to afford yellow powder. $\left(\mathrm{CH}_{2} \mathrm{Cl}_{2} /\right.$ petroleum ether $=1: 1$; $\mathrm{CH}_{2} \mathrm{Cl}_{2}$ /ethyl acetate $=20: 1$ ). Yield: $58 \%$.

\section{RESULTS AND DISCUSSION}

The synthetic routes of monomers and polymer are presented in Scheme 2. First 2,5-bisbenzoylterephthalicazide (2a) and 2,5-bis(4-methoxy-benzoyl)terephthalicazide (2b) were readily synthesized from pyromellitic dianhydride in two steps. The first step is a Friedel-Craft reaction between dianhydride and benzene or anisole to give several isomers. The isomers were separated by fractional recrystallization from glacial acetic acid. The products were converted to bisphthalicazide when treated with chloroformate followed by treatment with sodium azide. Two polymers PBDA-a and PBDA-b were synthesized via one-pot reaction of compound $\mathbf{2 a}$ and $\mathbf{2 b}$, respectively in a yield of $69 \%$ and $78 \%$ finally. The polymers are easily soluble in common solvents such as chloroform and tetrahydrofuran. The structure of 


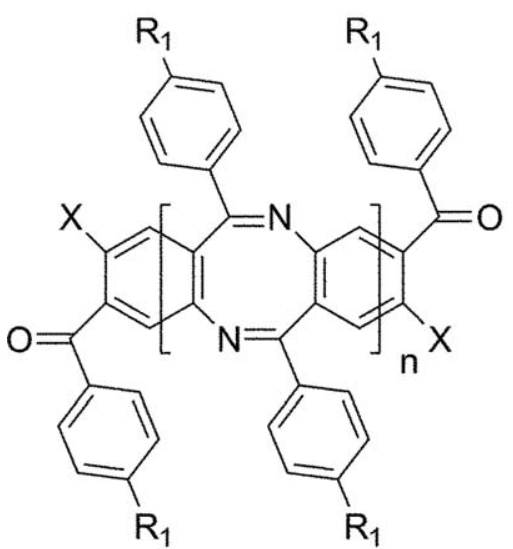<smiles>[R6][R6]([R6])([R6])[H]</smiles>

a

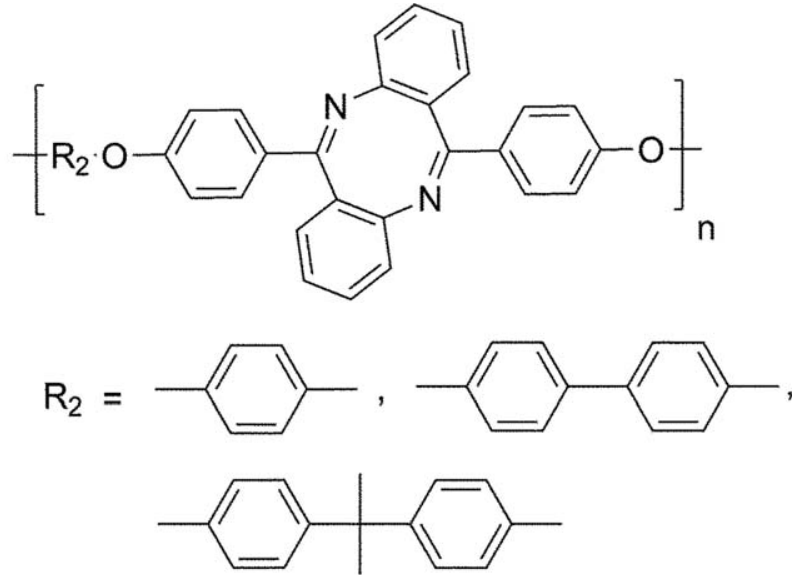

Conventional polydiazocines

FIGURE 1 Molecular structures of (a) ladder polydiazocines, (b) conventional polydiazocines.

polymers was carefully confirmed by FT-IR, NMR spectra, MALDI-TOF

FT-IR spectra of polydiazocines are shown in Figure 2. The presence of the strong absorption of $\mathrm{C}=\mathrm{N}$ at $1592 \mathrm{~cm}^{-1}$ and the weak absorption of carbonyl group at $1725 \mathrm{~cm}^{-1}$ suggests that the reaction occurred. ${ }^{1} \mathrm{H}$ NMR spectrum in Figure 3 exhibits two broad peaks around 7.80 and 6.87 ppm, which provided that the desired product may be formed. ${ }^{13} \mathrm{C}$ NMR spectrum of the product in Figure 4 provided further confirmation that the desired polymer had been formed, with the presence of carbons of $\mathrm{C}=\mathrm{N}$ being observed at $169 \mathrm{ppm}$ and the disappearance of signal at 193.7 ppm corresponding to carbonyl signal in $\mathrm{C}=\mathrm{ON}_{3}$ group.

The molecular weights and molecular weight distributions of the ladder polydiazocines were determined by GPC analysis with tetra-hydrofuran (THF) as eluent (Table 1). The weightaverage molecular weight (Mw) of PBDA-a and PBDA-b obtained from trifluoroacetic acid (TFA) solution were found to be $3.0 \mathrm{kDa}$ and $1.6 \mathrm{kDa}$, respectively. The PDI of PBDA-b is relatively narrow from 1.5 to 1.7 . Polymer PBDA-a obtained from anhydrous TFA could not be dissolved in THF. PBDA-b obtained from anhydrous TFA could not be separated by column chromatography and its PDI is rather wide as 6.58 .

MALDI-TOF measurements (Fig. 5) are not in agreement with the GPC data, but give additional information of the polymer. The predicted masses for this polymeric series ( $n$ $=1,2,3,4$ ) with bisamino-terminited structure are therefore $716.3,1056.4,1396.5,1736.6 \mathrm{~g} \mathrm{~mol}^{-1}$. The $\mathrm{m} / z$ ratio of one repeat unit of PBDA-b is $340.1 \mathrm{~g} \mathrm{~mol}^{-1}$. The mass spectra of oligomers display two polymeric series with peak repeat unit of $340.1 \mathrm{~g} \mathrm{~mol}^{-1}$ which is equal to the molar mass of the molecular unit. The $m / z$ ratio for the observed $\mathrm{Na}^{+}$ peaks is consistent with the formation bisamino-terminited oligomers, located at 1079.4, $1419.5 \mathrm{~g} \mathrm{~mol}^{-1}(n=2,3)$. The $\mathrm{m} / \mathrm{z}$ ratio for the other observed peaks located at 1515.5 , 1855.6, $2196.7 \mathrm{~g} \mathrm{~mol}^{-1}$ with a repeat unit of $340.1 \mathrm{~g} \mathrm{~mol}^{-1}$ the molar mass can associated to one amino group and one $\mathrm{NHCOCF}_{3}$ group trapped oligomers $(n=3,4,5)$. Oligomers with two $-\mathrm{NHCOCF}_{3}$ group with four repeat units can also be found at $1941.6 \mathrm{~g} \mathrm{~mol}^{-1}$ the molar mass. All of the results are consistent with the formation of polydiazocine. The mechanism of the polydiazocine synthesis is assumed to condensation polymerization proceeding by an unprecedented cyclization of the isocyanate with the neighboring acyl group, followed by the dimerization to form diazocine ring and release dioxide in our previous work. ${ }^{23}$

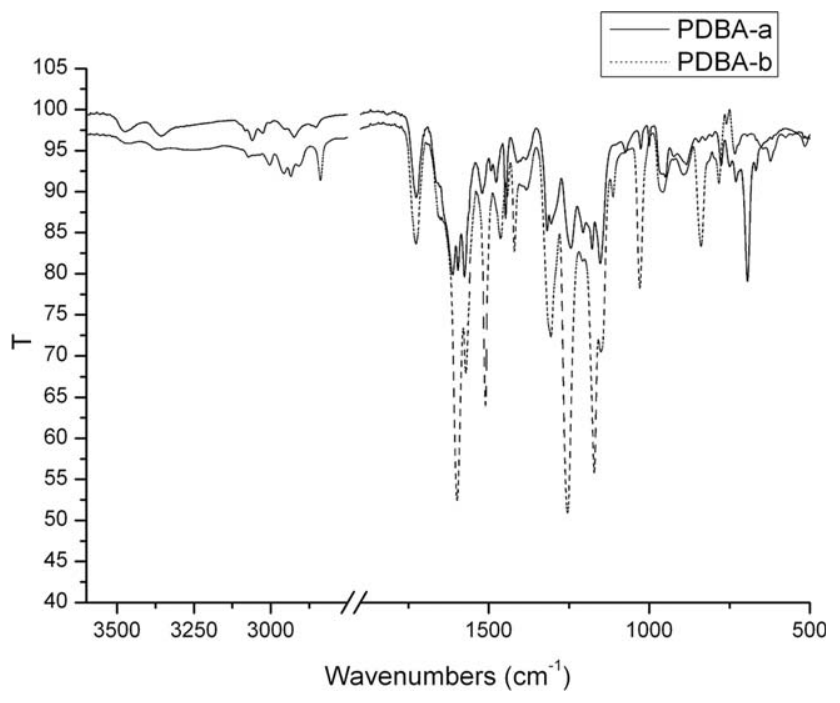

FIGURE 2 FT-IR spectra of polydiazocines. 

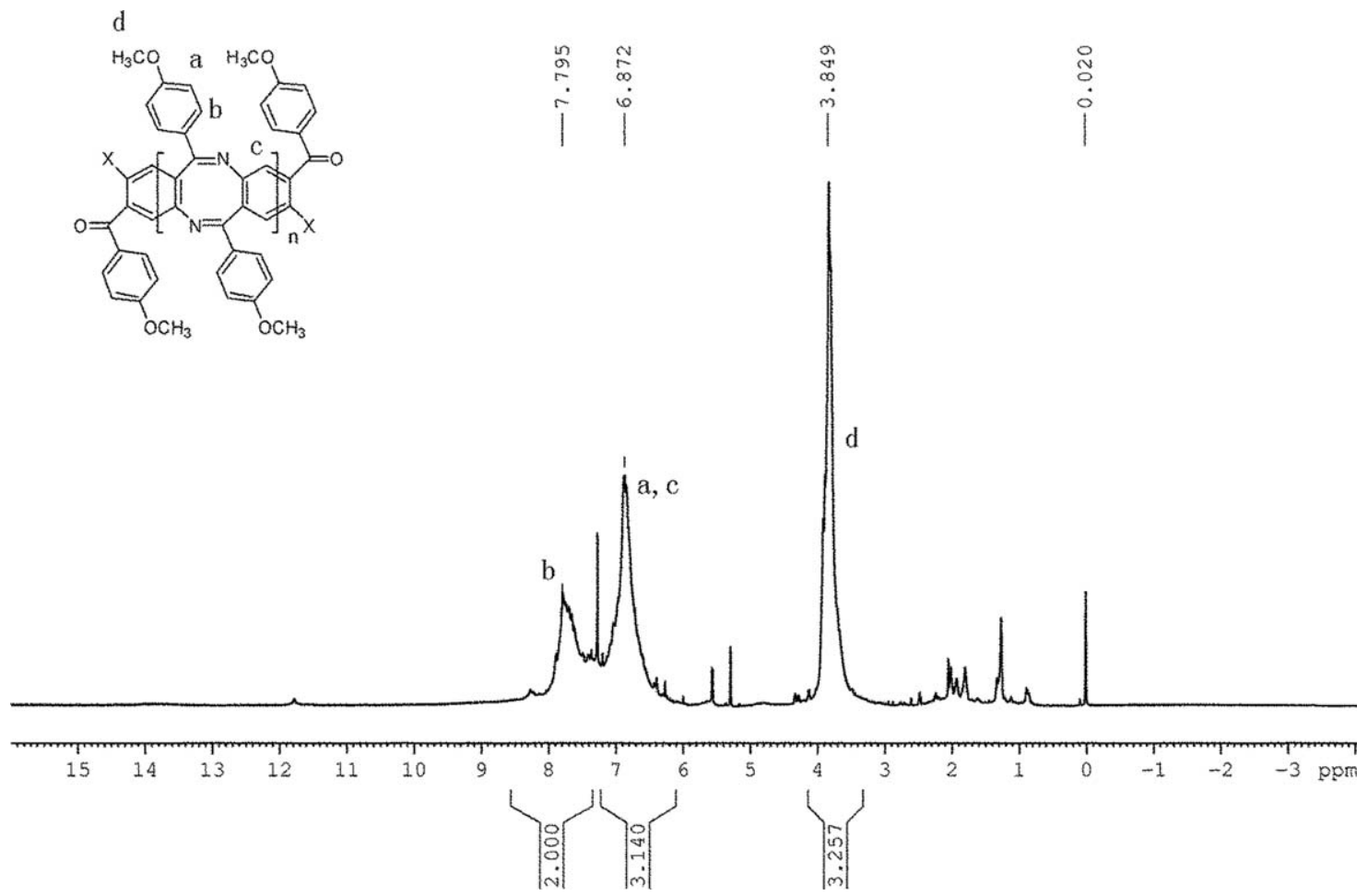

FIGURE $3{ }^{1} \mathrm{H}$ NMR spectrum of PBDA-b.

To determine the thermal properties of PBDA-a and PBDA-b, TGA and DSC had been performed under nitrogen. As shown in Figure 6, PBDA-a and PBDB-b show weight loss at 300 and $310{ }^{\circ} \mathrm{C}$, respectively. Both of them exhibit excellent thermal stability with the decomposition temperature $(5 \%$ weight loss) above $350{ }^{\circ} \mathrm{C}$. This result shows that the polymers match well with the fabricating needs of organic electronic devices. Besides, DSC results show that no phase transitions were detected during the scan of both polymers from 50 to $280{ }^{\circ} \mathrm{C}$.

The UV-Vis absorption spectra of polydiben-zoylazocines solution in dichloromethane at a concentration of $10^{-5} \mathrm{M}$ are presented in Figure 7. As depicted, in solution PBDA-a
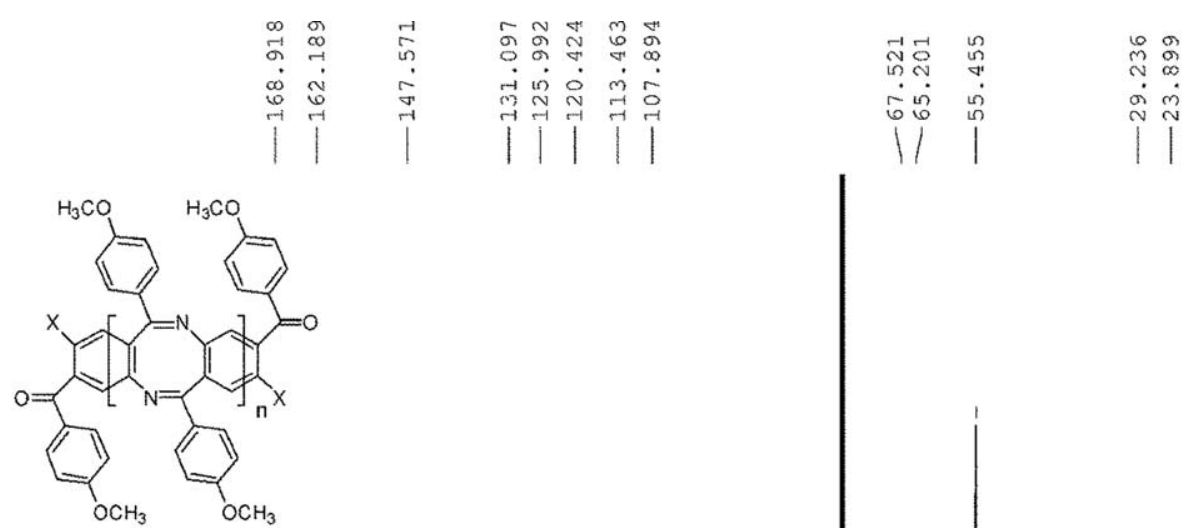
TABLE 1 GPC Data of the Ladder Polydiazocines

\begin{tabular}{|c|c|c|c|c|}
\hline Sample & Yield (\%) & $M_{\mathrm{w}}$ & PDI & Solubility in THF \\
\hline PBDA- $a^{a}$ & 78 & 3027 & 1.51 & + \\
\hline PBDA-b ${ }^{a}$ & 58 & 1597 & 1.67 & + \\
\hline PBDA-a ${ }^{b}$ & 97 & - & - & - \\
\hline PBDA-b ${ }^{b}$ & 98 & 27611 & 6.58 & + \\
\hline
\end{tabular}

and PBDA-b have maximum absorption wavelength similar to the absorption of their diazocine rings. Both of the spectra have about $5 \mathrm{~nm}$ red-shift. The absorption red shift compared with one ring diazocine is symptomatic of the extended conjugation in the polymer. The maximum absorption wavelengths of PBDA-a and PBDA-b are located at 267 and $291 \mathrm{~nm}$, respectively. No photoluminescence of the small

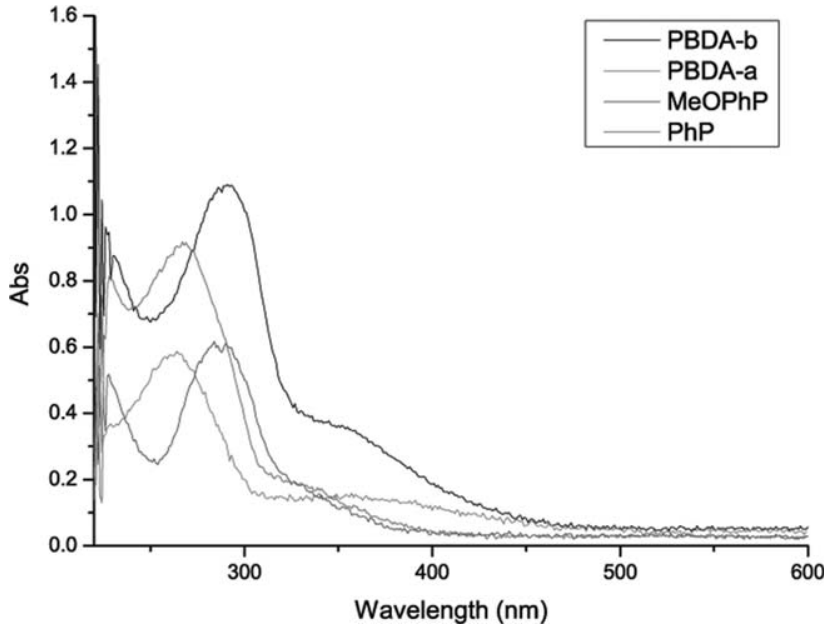

FIGURE 7 Absorption spectra of PBDA-a, PBDA-b, 6,12-bis(4methoxyphenyl) dibenzo[b,f][1,5] diazocine (MeOPhP) and 6,12diphenyldibenzo $[\mathrm{b}, \mathrm{f}][1,5]$ diazocine $(\mathrm{PhP})$.
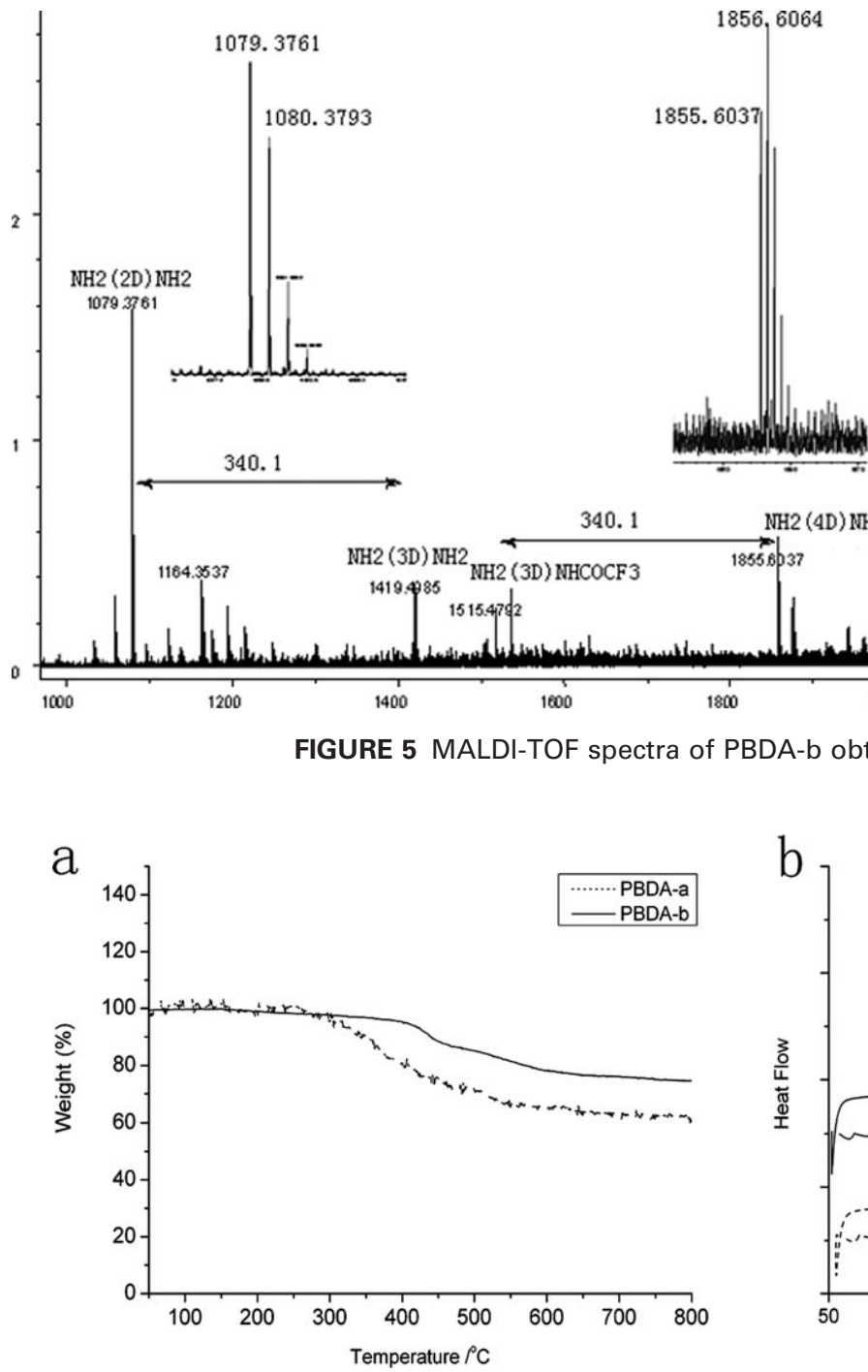

FIGURE 6 TGA (a) and DSC (b) curves of polydiazocines. 


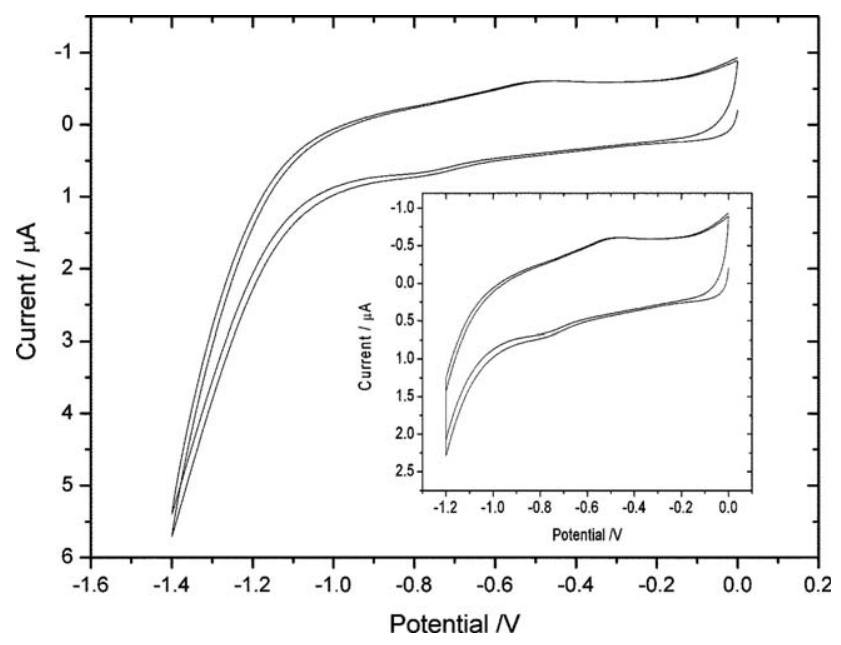

FIGURE 8 Cyclic voltammograms of PBDA-b in a $1.0 \mathrm{~g} / \mathrm{L}$ THF solution with $0.1 \mathrm{M} \mathrm{N}(\mathrm{C} 4 \mathrm{H} 9)_{4} \mathrm{ClO}_{4}$ as the supporting electrolyte under, $100 \mathrm{mV} / \mathrm{s}$, three cycles. $\mathrm{Fc} / \mathrm{Fc}+$ ) $0.45 \mathrm{~V}$ vs. $\mathrm{Ag} / \mathrm{Ag}+$. molecules or polymers can be observed in dichloromethane at a concentration of $10^{-5} \mathrm{M}$.

The cyclic voltammogram of PBDA-b is shown in Figure 8. The two hetero atoms of the diazocine unit contributed to the redox stability of the 8-membered ring. Cathodic potential scan produced one reduction peaks at $-0.76 \mathrm{~V}$ vs. $\mathrm{Ag} / \mathrm{Ag}+$, and the corresponding oxidation peaks at $-0.51 \mathrm{~V}$ appeared under inert conditions. The reduction peaks at $-1.23 \mathrm{~V}$ was not found, which is different from results in literature. ${ }^{19}$

The calculations are performed with the density functional theory method (B3LYP) at the 6-31G(d,p) basis set level implemented with the Gaussian 09 program in Figure 9. For the dimer and trimer of $[1,5]$ diazocine, the ring structure (Dim and Tri) and the zigzag conformation (Dim[lowem]ZZ and Tri[lowem]ZZ) are designed. The optimization illustrates that the ring structure is higher in energy than that of the zigzag conformation owing to the strong steric effect of the neighboring fluorine benzene groups. While, when the

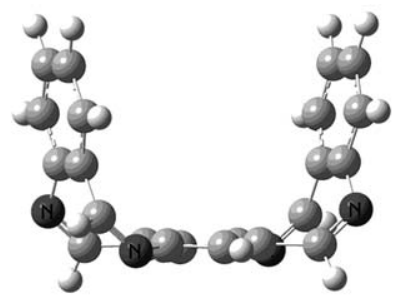

Dim

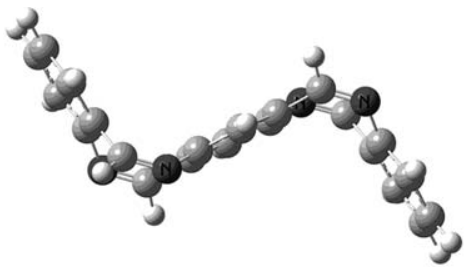

Dim-ZZ

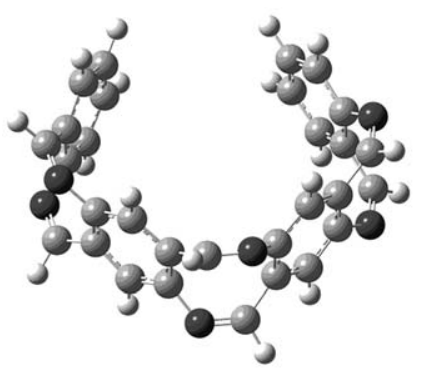

Tri

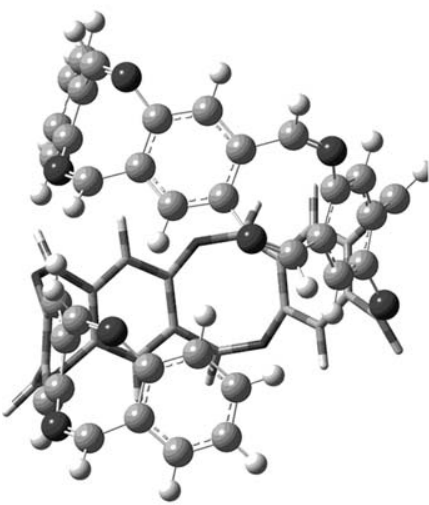

Hexa

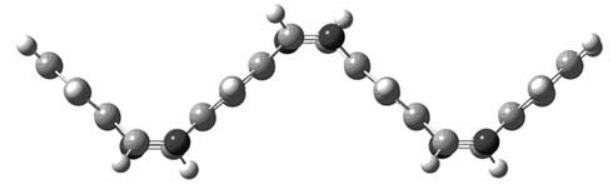

Tri-ZZ

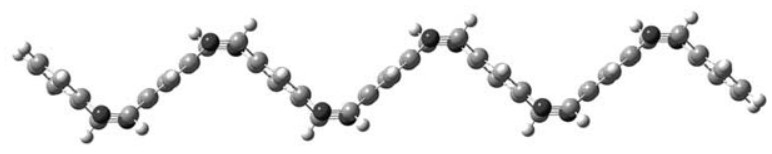

Hexa-ZZ

FIGURE 9 Molecular conformational model of the polydiazocines with different rings. 
fluorine benzene groups are substituted with the hydrogen atoms (DimH, TriH, DimH[lowem]ZZ and TriH[lowem]ZZ), the steric effect disappears. The polymer of $[1,5]$ diazocine prefers to the ring structure rather than the zigzag conformation, as indicated by their relative energies.

With the increase of the degree of the polymer, the ring structure changes to the helix conformation. We also performed the calculations for hexamer of [1,5] diazocine to verify the above conclusions. These optimizations were performed at B $3 L Y P / 3-21 G^{*}$ level for this system with the consideration of the computational consumption. The results demonstrate that the zigzag structure is preferred for the system with the fluorine benzene groups. While, the helix conformation is lower in energy for the hydrogen substituted hexamer. Therefore, the zigzag structure is preferred for the systems with the fluorine benzene side chain owing to their strong steric effect, and the helix conformation is more stable than the zigzag one for the hydrogen substituted systems. The calculations with functional theory method support that compound PBDA-a preferred to display helix conformation. Compounds PBDA-b with methoxylphenyl group preferred to display zigzag conformation structures like PBDA-F owing to their strong steric effect.

\section{CONCLUSIONS}

Novel polydiazocines containing the diazocine unit has been synthesized via one-pot polymerization, and their molecular structures are confirmed by ${ }^{13} \mathrm{C}$ NMR, IR and MALDI-TOF. Electrochemical, absorption spectral and thermal properties of polymers have been investigated. The resulting polymers exhibit good solvent solubility, enhanced thermal stability $\left(T_{\mathrm{d}} 5 \%=\right.$ $350{ }^{\circ} \mathrm{C}$ ). The results of polymer calculations using the density functional theory method reveal the methoxy-substituted polymer PBDA-b prefers to display the zigzag conformation and hydrogen-substituted polymer PBDA-a prefers to display the helix conformation structure. The new polydiazocines with excellent thermal stability may have potential application as molecular actuator and other organic electronic devices.

\section{ACKNOWLEDGMENTS}

We appreciate the financial support from NSFC (21174157), Natural Sciences Foundation of Shandong Province
(BS2009CL026) and Qingdao Agricultural University Research Foundation (631222).

\section{REFERENCES AND NOTES}

1 D. A. Scherlis, N. Marzari, J. Am. Chem. Soc. 2005, 127, 3207. 2 W. Lu, A. G. Fadeev, B. Qi, E. Smela, B. R. Mattes, J. Ding, G. M. Spinks, J. Mazurkiewicz, D. Zhou, G. G. Wallace, D. R. MacFarlane, S. A. Forsyth, M. Forsyt, Science 2002, 297, 983.

3 H. Chen, Y. Guo, X. Sun, D. Gao, Y. Liu, G. Yu, J. Polym. Sci. Part A: Polym. Chem. 2013, 51, 2208.

4 F. Terao, M. Morimoto, M. Irie, Angew. Chem. Int. Ed. Engl. 2012, 124, 925.

5 K. Y. Cho, S. S. Hwang, H. G. Yoon, K. -Y. Baek, J. Polym. Sci. Part A: Polym. Chem. 2013, 51, 2208.

6 Y. Wu, G. Alici, J. D. W. Madden, G. M. Spinks, G. G. Wallace, Adv. Funct. Mater. 2007, 17, 3216.

7 D. Chao, X. Jia, H. Liu, L. He, L. Cui, C. Wang, E. B. Berda, J. Polym. Sci. Part A: Polym. Chem. 2011, 49, 1605.

8 A. S. Hutchison, T. W. Lewis, S. E. Moulton, G. M. Spinks, G. G. Wallace, Synth. Met. 2000, 113, 121.

9 S. Koh, T. Li, J. Zhou, X. Zhao, W. Hong, J. Zhu, Z. Suo, J. Polym. Sci. Polym. Phys. 2011, 49, 504.

10 M. J. Marsella, Acc. Chem. Res. 2002, 35, 944.

11 M. J. Marsella, R. J. Reid, Macromolecules 1999, 32, 5982.

12 M. J. Marsella, R. J. Reid, S. Estassi, L. S. Wang, J. Am. Chem. Soc. 2002, 124, 12507.

13 C. Song, T. M. Swager, J. Org. Chem. 2010, 75, 999.

14 C. Song, D. B. Walker, T. M. Swager, Macromolecules 2010, 43, 5233.

15 C. Schnieders, W. Huber, J. Lex, K. Mullen, Angew. Chem. Int. Ed. Engl. 1985, 24, 576.

16 L. A. Paquette, Acc. Chem. Res. 1993, 26, 57.

17 F. -G. Klarner, Angew. Chem., Int. Ed. 2001, 40, 3977.

18 E. L. Spitler, C. A. Johnson, M. M. Haley, Chem. Rev. 2006, $106,5344$.

19 T., Suga, S. Wi, T. E. Long, Macromolecules 2009, 42, 1526

20 C. Hoppin, R. B. Bates, C. G. Contreras, A. Somogyi, M. J. Streeter, Jr., H. K. Hall, Polym. Bull. 2009, 63, 509-515.

21 B. Dolenský, M. Valík, D. Sýkora, V. Král, Org. Lett. 2005, 7, 67.

22 X. Wang, J. Li, N. Zhao, X. Wan, Org. Lett. 2011, 13, 709.

23 N. Zhao, L. Qiu, X. Wang, J. Li, Y. Jiang, X. Wan, Tetrahedron 2012, 68, 9665. 